\title{
DIMENSIONS AND LOCATION OF HIGH-INVOLVEMENT MANAGEMENT: FRESH EVIDENCE FROM THE UK COMMISSION'S 2011 EMPLOYER SKILLS SURVEY
}

High-involvement management is typically seen as having three components: worker involvement, skill and knowledge acquisition and motivational supports. The prescriptive literature implies the elements should be used together; but using data from the UK Commission's Employer Skills Survey of 2011 we find that these dimensions of highinvolvement management are in reality separate. Two types of involvement, role and organizational, are not strongly related, and motivational supports are not strongly correlated with other practices or each other. Size of workplace and the sector in which it operates are associated with the dimensions of high-involvement management. But, there is variety in their other predictors. For example, organizational involvement and skill acquisition are positively related to workplace size while role involvement is negatively associated with it. The research illustrates the value of scaling methods over blanket indexes to measure high involvement management and highlights the independent effects of quality and operational management methods. 


\section{INTRODUCTION}

High-involvement management remains at the centre of modern management thinking, as the virtues for a fast-changing economy of a specific system of human resource management (HRM), centred on employee involvement and development, are espoused. High-involvement practices are widely taken to include enriched job design, team work, functional flexibility, idea-capturing, intensive training and development, information-sharing and appraisal (Appelbaum et al., 2000; de Menezes and Wood, 2006; Kalleberg et al., 2006). Allied to these are motivational practices, which are aimed at aligning individual and organizational goals and requirements, such as performance-related pay, equal-opportunities policies, and work-life balance policies. It is typically advocated that such practices should be used together and viewed as a synergistic set.

The concept of high-involvement management spawned a large stream of research, testing whether such an approach was associated with higher organizational performance (Guest, 2011; Wall and Wood, 2005; Wood, 1999). Much of this produced positive results, but these were not always consistent across surveys or performance measures within the same survey. Moreover, the variety of practices across studies, as well as the methods of developing composite methods, means that it is difficult to make firm conclusions about which practices are decisive for performance, or whether indeed the total set is required.

Initial studies centred on Lawler's (1986) and Walton's (1985) attempts to define a HRM model based on the importance of job design, and this gave some rationale for the practices included in them. But, even in these studies there appeared to be an element of expediency, as practices that reflected innovations in the industries studied (e.g. Arthur, 1994) or sophisticated personnel management, such as job 
analysis, were included (e.g. in Huselid, 1995). And many studies excluded Lawler's and Walton's foundation, role involvement, a tendency that Wood and Wall (2007) showed reflected an increasing focus, following resource-based theory, on human resources as potentially unique assets at the expense of the empowerment of nonmanagerial staff (e.g. Becker and Huselid, 1998).

Consequently, on the one hand, the selection of practices seems sometimes to be based more on intuition about what might influence performance than any theoretical foundation or solid empirical evidence. Yet, on the other hand, several studies make overt use of what is typically known as AMO (Ability + Motivation + Opportunity to Participate) theory (Boxall and Purcell, 2003; Gerhart, 2007: 318-322). It is effectively an extension to the organizational level of the psychological theory that individual performance is based on abilities, knowledge and motivation. It also includes the opportunities individuals have for involvement and the way their work context is designed to aid this. It thus differentiates three dimensions or subsystems of high-involvement management: (1) a work-organization element which is about the opportunities for employee involvement and participation, (2) a training and development component which is concerned with human capital or skill and knowledge acquisition, and (3) a motivation-enhancement component that involves incentives to perform in order to ensure that employees are motivated to use their discretion in line with the organization's objectives (Appelbaum et al., 2000; Kalleberg, et al., 2006; de Menezes and Wood, 2006).

The prescription underlying the high-involvement management concept is that the practices associated with this triad ought to be used together. Nevertheless, the limited tests of whether the types of practices are used in concert have suggested they may not (de Menezes and Wood, 2006). Moreover, within studies of their 
performance effects, those assessing the impact of subdivisions of practices have perhaps produced the most promising results: different subsets may be more significant for performance than others, or may influence performance through distinct routes (Subramony, 2009; Wood, et al., 2012).

In this paper we test whether all the practices associated with high-involvement management tend to co-exist, or whether various sets of practices form discrete elements. We then examine how this reflects the differences in the predictors of the use of each dimension - that is variations between the dimensions in the types of organizations that score high on each. The research is based on data from the UK Commission's Employer Skills Survey of 2011.

\section{HIGH-INVOLVEMENT MANAGEMENT}

\section{High-Involvement Management}

High-involvement management is often treated as synonymous with highperformance work systems, but this is to prejudge its performance effects. Moreover, it risks underplaying differences in the HRM literature as to what are the critical components within HRM systems for performance. High-involvement management's focus on employee involvement is popular, but by no means universal. Such labels describe what Boxall and Macky (2009:8) call "the dominant theme informing a stream of managerial action" in which we are interested. Applying this notion, highinvolvement management may be differentiated from Walton's (1985) highcommitment management, when the two are often treated as synonymous. For, while in both concepts empowerment is the bedrock of the system of management, 
the dominant theme of the high-commitment approach is, as Boxall and Macky (2009) say, its orientation towards enhancing commitment. In their terms, the practices most associated with this are not involvement practices, but such employment practices as, for example, job security guarantees. In our terms these are motivational practices. (Given Walton's focus we might in fact conclude that highinvolvement management is a better label for what he is modelling.)

Lawler's and Walton's concepts both grew out of their earlier concern with work enrichment as it was realised that for successful job redesign, the context needed to be changed to support these, and successful employee involvement entailed organizational and not just role involvement. Redesigning jobs so they "combine planning and implementation" (Walton, 1985: 79), and avoid the narrow job specifications and rigid divisions of labour associated with Taylor's Scientific Management, is the bedrock of high-involvement management (Boxall and Macky, 2009:9). But high-involvement management entails going beyond redesigning jobs, as it means workers participating not only in changing their roles, but also in what Benson and Lawler (2003:156) call "opportunities to...participate in the business as a whole". This organizational participation or involvement is distinct from the role involvement associated with work enrichment (Wall, Wood and Leach, 2004), and high-involvement management entails both role- and organizational-involvement practices, as well as those that enhance the skills and knowledge of workers required for this involvement, and that ensure the types of rewards they receive are supportive of involvement. Thus Lawler's (1986) high-involvement management model is multifaceted, with power the first of its four dimensions, the others being information-sharing, developing knowledge, and rewarding performance. Role- and organizational involvement are about ensuring that power is distributed to lower 
levels of the organization, so that decisions can be decentralized or made collectively with the maximum input from those who have expertise in the area. In Wood's (2009) terms, a key aspiration behind high-involvement management is the development of broader horizons amongst all workers so that they will think of better ways of doing their jobs, connect what they do with what others do, and take initiative in the face of novel problems. We treat the other three dimensions in Lawler's terms - information-sharing, developing knowledge and rewarding performance - as supports to this development and decentralized decision-making.

\section{The integrated or fragmented use of High-Involvement Practices}

The commonplace prescription of an integrated approach to high-involvement management, in which the AMO's triad of types of practices are used in concert, is based on the assumption that returns from increasing the use of practices ought to increase exponentially, as there will be synergistic effects between the practices. Nonetheless, different emphases are given to the components of HRM systems. For example, while in our high-involvement perspective involvement is the core element of the approach and the other elements are supports for achieving this, in a performance-management approach the motivational supports might be prioritised.

In reality, practices might not be used in conjunction with each other, and if managements give differing emphases to the elements, then different approaches to HRM will materialise across the economy. If, for example, the focus is on intensive training and development, then this might represent what Dyer and Holder (1988) call an investment approach to HRM. The extreme contrast would perhaps be between the high-involvement approach and Dyer and Holder's (1988) incentives approach, which is focused on directly rewarding performance and motivational practices such as performance-related pay. 
If managements are giving different emphases to components of the AMO model, the total package of practices might not be used as the prescriptive model implies it should. In particular, the use of motivational supports such as performance-related pay systems may be less correlated with other practices, because they can act as incentives to the achievement of the organization's demands regardless of the nature of these, or the management system involved. In addition, motivation practices associated with high-involvement management may be substitutes for each other, and hence not be highly correlated amongst themselves. De Menezes and Wood's (2006) analysis of the 1998 British Workplace Employee Relations Survey (WERS) has indeed shown that motivational practices tend neither to be strongly correlated nor associated with either role- or organizational-involvement practices, a finding that was supported by the data in the 2004 WERS (Wood, et al., 2012) and by our preliminary analysis of 2011 WERS.

A second divergence from the prescriptive model (de Menezes and Wood, 2006; Wood et al., 2012) is the lack of correlation between role involvement and organizational involvement. Evidence again from analysis of WERS (1998, 2004 and 2011) show that role- and organizational involvement are indeed distinct and very weakly correlated ( $r=0.07$ in 2004; 0.06 in 2011).

In de Menezes and Wood's study (2006), the measures of skill development were concerned with practices aimed at supporting involvement, such as the disclosure of financial information and training in team working or interpersonal skills. These practices were found to be correlated with organizational involvement practices such as quality circles and team working. General training was not, however, correlated with organizational involvement and we might expect this to be typically the case. 
Studies that have linked subsystems of high-involvement management to performance have found differing relationships across the subsystems (Huselid, 1995; MacDuffie, 1995; Wood and de Menezes, 2008). For example in Wood et al. (2012), role involvement had a stronger relationship with productivity measures than organizational involvement. MacDuffie (1995) differentiated work systems (equivalent to work organization or opportunities for participation) from human resource systems (a combination of skills and motivational elements), and found in his cross-national study of car factories that, while both were associated with quality, only work systems were related to productivity. A meta-analysis of mainly US studies comparing subsystems found that empowerment practices (job design and highinvolvement practices) were more strongly related to various performance indicators than were combinations of all HRM practices (Subramony, 2009). Such results, and what we know from the studies that have identified subsets, suggest that we need to be especially cautious about the conclusions that may be drawn from studies that do not include good discrete measures of both role- and organizational involvement.

More generally we need to be particularly cautious about - or even forsake - the simple aggregation of practices to form global indexes (Datta, Guthrie and Wright, 2005; Guest and Hoque, 1994; Way, 2002; West et al., 2006) which may mask important differences between organizations. Indexes may give the same score to organizations whose HRM practices are dominated by one or other of involvement, skill acquisition and motivational practices. For example, if an organization has merit pay, promotion on merit and profit-sharing, and no involvement practices, and another has quality circles, functional flexibility, and teamwork, they would be scored three on an index, but could have very different HRM philosophies. The need is for 
more studies that measure all elements of HRM systems with a range of practices and then, prior to any analysis of their antecedents or performance effects, assess their associated use in order to establish meaningful differentiations between sets of practices and identify the underlying orientations that exist in reality.

If the normative strategic model that prescribes that high-involvement practices should be used together is followed in practice, we would expect them to co-exist, and the pattern of association between practice-use to be a one-dimensional structure. At the other extreme, if the four dimensions we have identified are distinct, we would expect a four-dimensional structure, with the tendency for each of roleinvolvement, organizational-involvement, skill-acquisition and motivational practices to co-exist, and the pattern of associations within each set of practices to be a onedimensional structure. We thus formulate and test the following hypotheses:

H1a: Role-involvement practices co-exist, and the pattern of association among them reduces to a one-dimensional structure.

H1b: Organizational-involvement practices co-exist, and the pattern of association among them reduces to a one-dimensional structure.

H1c: Skill-acquisition practices co-exist, and the pattern of association among them reduces to a one-dimensional structure.

H1d: Motivational practices co-exist, and the pattern of association among them reduces to a one-dimensional structure.

H1e: The practices within each type of high-involvement practice co-exist, and the pattern of association amongst all high-involvement practices reduces to a four-dimensional structure. 
However, because of the uncertainty surrounding the nature and origin of motivational practices, we might expect no strong pattern to their use - in which case, the competing hypothesis to $\mathrm{H} 1 \mathrm{e}$ is:

H2: The practices within role-involvement, organizational involvement and skill acquisition co-exist, and the pattern of association amongst all highinvolvement practices reduces to a three-dimensional structure.

\section{PREDICTORS OF THE USE OF HIGH-INVOLVEMENT MANAGEMENT}

There are few studies of the predictors of the adoption of high-involvement practices. There are no strong theories explaining why managements will introduce them, or in which types of workplaces they are most likely to be found. Factors typically included in discussions are sector, organizational size, strategic context, and operationalmanagement methods. Such discussions are mainly about the use of HRM systems in general, but the more fragmented the use of such practices, the greater the likelihood that the predictors of their use will differ.

The most in-depth discussion of diversity in predictors, by Kalleberg et al. (2006), stresses the difference between the predictors of performance-based incentives, a motivational practice, and the other types of practices. Focusing on sector differences, they hypothesize and find that incentives are more likely to be used in for-profit-sector organizations than non-profit or public-sector organizations, while teams, a measure of opportunities for participation, are less likely in for-profit-sector organizations than non-profit or public-sector organizations. There are no sectorial differences for their measure of skill acquisition.

We follow Kalleberg et al.'s theory (2006) and argue that the public sector is more likely to use role-involvement, organizational-involvement and skill-acquisition practices, and less likely to use motivational devices. Concern for individual 
development and involvement may be stronger in the non-profit sector, partly because pressures for public-sector organizations to be seen to be good employers may still exist, as in institutional theory (DiMaggio and Powell, 1991).

We also hypothesize, however, that the nature of the work may be important - in particular, that being a provider of services may be significant on the grounds, for example, that there is a closer relationship between employees and the customer in the provision of services than in non-services. This would apply to private and public services, and thus in our research we differentiate between private- and publicsector organizations, and distinguish between primary industry, construction and manufacturing. We therefore test:

H3a: The use of role-involvement, organizational-involvement and skillacquisition practices will be greater in workplaces in the private and public services.

H3b: The use of motivational supports will be greater in private-sector workplaces.

Organizational size is often considered as a factor explaining adoption of highinvolvement management because of economies of scale in human-resource practices, and because large organizations in the public domain need to be seen to involve and develop workers. Kalleberg et al. (2006: 279) add that there is greater need for large organizations to divide the organization into small units through teams and other involvement practices. However, this implies that small organizations are already in the same form and that they "naturally" involve people more. We hypothesize that this is the case, but conjecture that involvement in small organizations is likely to be most pronounced in the case of role involvement and that, while workforce morale and cohesion may be greater in small organizations, 
organizational-involvement methods such as formal teams and idea capturing schemes, or information-sharing may not be so prevalent. Thus we hypothesize:

H4a: The use of role-involvement practices will be greater in smaller workplaces.

H4b: The use of organizational-involvement and skill-acquisition practices and motivational supports will be greater in larger workplaces.

We differentiate between the organisation's product-market strategy, basic mode of production, and methods of quality controls, and argue that all are sufficiently independent to have a unique impact on the use of high-involvement practices. To differentiate strategic contexts we use Porter's (1980) distinction between costminimization and innovative/quality strategies, and hypothesize that highinvolvement systems fit the innovative/quality strategy, as their fulfilment requires a high-skilled, involved, cohesive and conscientious workforce, while the Taylorist lowinvolvement management is more appropriate for the cost-minimization strategy (Schuler and Jackson, 1987; Hoque, 1999). Accordingly:

H5: The use of role-involvement, organizational-involvement, skill-acquisition practices and motivational supports will be greater in workplaces that are competing on non-price dimensions, have a high-quality-oriented strategy, or are product leaders.

Production or service delivery systems may be differentiated by whether the product or service is customized or mass produced. Customization is about "creating a closer fit with customer preferences' (Hong, et al., 2013), and thus a high level of involvement and engagement with both the customer and fellow workers is needed to display both service-offering and interpersonal adaptive behaviour (Gwinner, Bitner, Brown and Kumar, 2005). Batt (2000) and Hong et al. (2013) directly link 
customization to high-involvement management, as it can foster these skills and customization requires flexibility, multitasking, problem-solving, team working, information seeking and empowerment. We thus test:

H6: The use of role-involvement, organizational-involvement, skill-acquisition practices and motivational supports is greater where production is customized.

Finally, quality-management systems can be differentiated on the basis of the extent to which they follow Total Quality Management (TQM). This includes methods such as just-in-time and self-inspection of work that aim to continually enhance quality and reduce waste in ways that simultaneously increase productivity. TQM and lean methods imply more than a set of operational techniques, but entail empowering workers, continuous skill development and organizational involvement through the use of idea-capturing schemes, team working and functional flexibility (Wood, 1991). It is thus commonplace in the literature on TQM and lean production to argue that high-involvement management is needed to support the operational techniques of TQM (Bou and Beltran, 2005; de Menezes et al., 2010; Kufidu and Vouzas, 1998). This is a normative thesis, but it is highly likely that managements will, even if they do not initially embrace this viewpoint, come to realise its virtues.

We thus hypothesize that TQM will be a predictor of the use of role involvement, organizational involvement and skill acquisition. TQM and lean methods may be applied in assembly line situations (Boxall, 2012) so, though role involvement is lower in standardized systems, we expect that role involvement will be higher in such systems if TQM has an effect independently of the degree of customization. In the case of motivational supports, we follow the TQM leaders and argue that the use of individual incentives and other individualised motivational devices are antithetical to 
developing effective TQM and lead to plateau thinking and employees working around systems rather than improving them (Deming 1986; Scherkenbach, 1991; Scholtes, 1987: 8). They will thus be negatively related to TQM.

We therefore test:

H7a: The use of role-involvement, organizational-involvement and skillacquisition practices will be greater in workplaces with TQM.

H7b: The use of individual motivational supports will be lower in workplaces with TQM.

\section{THE STUDY}

To test the hypotheses, we use data from the UK Commission's 2011 Employer Skills Survey, which was a telephone survey consisting of over 87,500 interviews. This is a nationally representative survey of UK workplaces employing one or more individuals, which represents one of the largest employer skill surveys in the world. The sample frame was selected through a stratified random-sampling approach to include establishments in all UK nations, regions of the four nations, SIC-defined sectors and size bands. Telephone interviews lasting approximately 25 minutes were conducted with the most senior person responsible for human resources, recruitment and workplace skills. In total, 224,042 establishments were contacted with a response rate of $39 \%$.

Only half of the sample was asked about high-involvement practices, which reduced the sample to 44,691 establishments. The survey designers selected the practices in the survey on the basis of Belt and Giles' (2009) concept of highperformance working, which is centred on involvement and training. The practices are listed below. (The questions used are shown in Table A1 - all Tables marked A are in the appendix on the web.) 


\section{High-Involvement Practices}

Employee Involvement: Task discretion, Task variety, Problem-solving teams, Project teams, Team briefings, Suggestion scheme, Staff survey.

Skill Acquisition: Induction, Work-shadowing, Off-the-job training, On-the-job training, Training plan, Training budget, Annual performance review, Evaluation of training.

Motivational Practices: Organizational performance-related pay, Individual performance-related pay, Flexible benefits, Flexible working, Equal-opportunity policy.

Of the involvement practices, Task discretion and Task variety are concerned with role involvement, and the remaining six with organizational involvement.

\section{Predictors}

The predictors for all analyses are the Size of the company, the Sector in which the company operates, how much the production of the company is Customized, and if TQM exists. The product-strategy variables are only relevant for private-sector firms and cover the extent to which their market success depends on competing on price and on quality, and on whether the firm is a leader in product or service development. The correlations amongst the product-market variables, customized production and TQM as well as factor analysis confirmed that the three types of variables are discrete. The market variables are also sufficiently independent to be included in regressions together.

\section{Control Variables}

We use the Country in which the company operates and whether the company is part of a larger organisation as control variables. Definitions of all predictor and control variables are in Table A2. 


\section{THE RELATIONSHIPS AMONGST HIGH-INVOLVEMENT PRACTICES}

The use of high-involvement practices in 2011 in the UK varies across practices. The measures of role involvement (discretion, $87 \%$ and variety, $87 \%$ ) are the most common with team briefings (79\%) and access to flexible working (78\%) close behind, though the latter is encouraged by legislation. Most skill- and knowledgeacquisition practices are used in between $40 \%$ and $50 \%$ of workplaces. The spread in the use of motivational supports is particularly large, the proportion of workplaces using them ranging from the $78 \%$ for flexible working to $21 \%$ for individual performance-related pay (see Figure 1).

\section{- Insert Figure 1 -}

If the correlations between practices are approximately uniform across all pairs, then this suggests that all high-involvement practices tend to be used together. However, if they are not, this indicates a more fragmented use consistent with our proposition that there are separate dimensions to the high-involvement systems. Analysis of the correlations between practices in the role-involvement, organizational-involvement, skill-acquisition and motivational groups revealed that the relationships within each are stronger than those involving pairs between groups (Tables A3-A5). The average correlation between pairs of practices within the same grouping is 0.49 , whereas the average correlation between pairs that span groups is 0.30, a statistically significant difference. We can see from Table A3 that task discretion and variety are only weakly correlated with the other involvement practices, whereas they correlate quite strongly with each other. This suggests two distinct factors underlie the use of involvement practices, which is consistent with the classification into role involvement and organizational involvement, as assumed in 
$\mathrm{H} 1 \mathrm{a}$ and $\mathrm{H} 1 \mathrm{~b}$. In the case of skill acquisition (Table A4), all correlations are high, suggesting (as in $\mathrm{H} 1 \mathrm{c}$ ) that there may be only one underlying factor, whereas Table A5 shows that a number of motivational practices are only weakly correlated, which indicates a fragmented use that may not be consistent with $\mathrm{H} 1 \mathrm{~d}$.

An attempt to fit a factor model to all high-involvement practices revealed that motivational supports do not fit with the other elements, nor does a unidimensional structure underpin them. The associations amongst the motivational supports do not reflect a common factor. Thus their adoption is idiosyncratic, as they may be treated as substitutes, or their use may be to support non-high-involvement approaches. Neither H1d nor H1e is thus supported.

A factor model could however be fitted to the data when motivational practices were excluded. Table A6 confirms that a single common factor does not underlie all the practices but rather that there are three groupings of practices consistent with those implied by the correlation matrices. $\mathrm{H} 1 \mathrm{e}$ is indeed not supported, but $\mathrm{H} 1 \mathrm{a}, \mathrm{H} 1 \mathrm{~b}$ and $\mathrm{H} 1 \mathrm{c}$ are, as is $\mathrm{H} 2$. Task discretion and variety form one group, while the other involvement practices, which all relate to organizational involvement, form a second, and the skill- and knowledge acquisition practices form a third unified group. Annual performance review contributes more to organizational involvement than to the skill acquisition factor.

These results suggest that we can measure the three identified dimensions using composite measures of them, based on the extent of practice use. As the factor loadings of practices are not that variable within each group, we will measure the three core elements of high-involvement management by counting the occurrence of each of the practices within each dimension. These will be used to test potential predictors of high-involvement management. In the case of motivational supports, 
each practice will be investigated separately. The distribution across practices is shown in Table A7.

\section{PREDICTING HIGH-INVOLVEMENT SYSTEMS}

\section{The economy}

To assess the predictors of the main elements of high involvement, we regress the three different dependent variables - role involvement, organizational involvement and skill acquisition - on employment size bands, sectors, customization, TQM, country, and part of a larger organization. Given that the three composite measures only take on positive integer values, we specify a Poisson model and estimate it with Maximum-Likelihood (Cameron and Trivedi, 2005: 666).

Role involvement is more prevalent in small workplaces (with less than 100 employees), in primary industries, public services and establishments with customized production systems (since standardized and partial customized production both have negative coefficients), but is less prevalent in manufacturing. It is also negatively associated with workplaces that are part of a wider organization, or are located in Northern Ireland or Wales (Table 1 col. 1).

The picture for organizational involvement (Table 1 col. 2) is different. Though more widespread in public services as role involvement is, it is less prevalent in small workplaces (with up to 100 employees) and primary industries, construction and manufacturing, relative to private services. There is also no association with the extent of customized production, but TQM has a positive relationship with organizational involvement when it was unrelated to role involvement. Being part of a wider organization has a positive association with organizational involvement and being in Wales is negatively associated with it. 
Skill acquisition (Table 1 col. 3 ) is again more prevalent in public services and less prevalent in small workplaces (with less than 50 employees) and in construction or manufacturing. In this case, TQM and customized production are significantly positively related to skill acquisition. But, unlike for role involvement, in this case partial customization is insignificant. Being part of a wider organization is significantly positively related to skill acquisition, as are being located in Northern Ireland and Scotland.

Consequently $\mathrm{H} 3 \mathrm{a}$ about sector differences is partially supported. Workplaces in public services have a higher level of all three dimensions than those in all nonservice sectors. In the case of other sectors, there is less consistency across dimensions. For example, primary industries have significantly higher levels of role involvement than workplaces in the private service sector, whereas they have lower levels of organizational involvement. $\mathrm{H} 4 \mathrm{a}$, that role involvement will be greater in smaller workplaces, is supported. The results for organizational involvement and skill acquisition are consistent with $\mathrm{H} 4 \mathrm{~b}$, as their levels are greater for workplaces with over 49 employees. H6, concerned with customization, is only supported for skill acquisition and role involvement; $\mathrm{H} 7 \mathrm{a}$, associating high-involvement systems with TQM, is supported for organizational involvement and skill acquisition. The significance of both quality and production systems is thus the most variable across the dimensions of high-involvement management.

We regressed each motivational support on employment size bands, sectors, customization, TQM, country, and being part of a larger organization, and these results are in Table A8. They show there is most support for $\mathrm{H} 7 \mathrm{~b}$ as TQM is associated positively with the majority of practices. Reflecting the fragmented 
relationship between motivational practices, the support for the other hypotheses varies across them. $\mathrm{H} 7 \mathrm{a}$, which posited a negative relationship between TQM and performance-related pay, the bête noire of TQM gurus, was not however supported.

\section{Private-Public Differences}

Analysing the private and public sector separately reveals one major difference: the relationship between customization and all the dimensions differs between the private and public sector (Table A9). In the public sector, customization is negatively related to all three dimensions, whereas it is positively related to them in the private sector. The less production or service in the private sector is customized, or the more it is standardized, the lower the level of role involvement, organizational involvement and skill acquisition. The exact opposite effect can be observed in the public sector.

The associations between customization and motivational supports also differ in strength and nature across the supports. In the private sector, workplaces with standardized production are less likely to have flexible benefits, flexible work and equal-opportunities policies. Organizational performance-related pay is most likely in standardized production systems, and more likely in partially-customized production than customized ones, but individual performance-related pay is only more likely in partially-customized production systems. However, in the public sector, the more customized the production or service, the more likely the workplace is to have organizational performance-related pay, individual performance-related pay, and flexible work, and the less likely it is to have equal-opportunity policies. In contrast, the results for TQM are very similar across sectors and the differences in the other 
predictors of motivational supports between the private and public sectors are minor (Tables A10 and A11).

\section{Private-Sector market variables}

Analysis of the private sector with the inclusion of all the strategy variables does not alter the significance of the other variables (Table 2). While non-price competition is unrelated to all dimensions of high-involvement management in this model, product leadership and competing on quality are positively related to all three. Analysis of non-price competition that excluded competing on quality revealed it is associated with role involvement, but its correlation with competing on quality means that it is not uniquely related to it. H5 is thus supported for role involvement, organizational involvement and skill acquisition, although non-price competition is not significant.

\section{- Insert Table 2 -}

The inclusion of the strategy variables into the motivational support models reduces considerably the associations involving customized production, and reveals that product leadership is significantly positively related to all with the exception of equal-opportunities policies. Non-price competition and competing on quality are unrelated to all motivational supports, except for individual performance pay, which is related to competing on quality (Table A12).

\section{CONCLUSION}

Overall, the study confirms that high-involvement management is constituted of three main elements, and as of now, at least in the UK, they are discrete and a fully integrated high-involvement management is not evident. A combination of factors predict variation in the dimensions: size, sector and strategy, which are related to all elements, and TQM and customization, which are each important for two. 
Prevalent concepts of high-involvement management assume that performance is affected by work organization, involvement, abilities and motivation. Consistent with this, we find that the practices that are related to each of the first three elements role involvement, organizational involvement and skill acquisition - each tend to be used together, but the three types are not necessarily used collectively; nor are they related to motivational supports, which themselves are not strongly related. Role involvement and organizational involvement practices are distinct from each other and from the skill-acquisition set. Consequently, we identified three dimensions of high-involvement management - role involvement, organizational involvement and skill acquisition - and classified the motivational supports as separate from each other.

We hypothesized a range of predictors of the use of these various dimensions of high-involvement management that included sectorial characteristics, workplace size, degree of customized production, use of TQM, and market context for privatesector organizations. Each of these factors predicted at least one dimension of highinvolvement management and there was support for all of our hypotheses, except for our conjecture that TQM would lead to lower use of motivational supports such as performance-related pay.

Sector and size (as well as being part of a larger organization) are significantly related to all three dimensions. But there are also some variations across the three dimensions in the type of sectors and size range that tend to score highly on them. In the case of the strategy variables, there is an association with all three dimensions; product leadership and competing on quality are uniquely associated with all, while the relationship between non-price competition was overridden by competing on quality. 
Two major differences across the dimensions of high-involvement management, however, stand out. First, TQM is associated with organizational involvement and skill acquisition but not role involvement. Second, customization is positively related to skill acquisition and role involvement when organizational involvement is not. In the case of role involvement, only a high level of customization is associated with it, so partial customization makes little difference, while the degree of skill acquisition is greater in partial customization and standardized production, though lower than in full customization.

In addition, customization relationships vary between the public and private sector. In the public sector, the association is negative and not as predicted, and more specifically those workplaces that are producing a customized service are more likely to have lower levels on all dimensions than where there is partial customization or standardization. The opposite effect is found for the private sector. Across the whole economy the differential sectorial effects of organizational involvement seem to cancel each other out, whereas in the case of role involvement and skill acquisition, customized production's positive effect in the private sector dominates.

This is the first study, to our knowledge, that has reported results linking customized and market variables to specific high-involvement management dimensions. Where our analysis is comparable with that of other studies of the relationship between practices or the predictors of high-involvement management, our results are not inconsistent with theirs. The assessment of the dimensionality of high-involvement management is in line with work on the WERS of both 1998 and 2004 (de Menezes and Wood, 2006; Wood and de Menezes, 2008). However, skillacquisition practices are not discrete from organizational-involvement practices in 
this work, which may be explained by the fact that the skill practices measured in the WERS studies are predominantly related to high-involvement working, e.g. training in interpersonal skills. The WERS studies did, however, show that general training was unrelated to either role- or organizational involvement, which is consistent with our findings.

Our analysis of the predictors that revealed a strong association between public services and high-involvement subsystems is consistent with Kalleberg et al.'s (2006) evidence that non-profit organizations tend to adopt them more. Our results on TQM are consistent with research based on the WERS data that shows that TQM or lean production is a major determinant of organizational involvement (de Menezes and Wood, 2006; Wood and Bryson, 2009) as does research using the Sheffield University Institute of Work Psychology Manufacturing Practices Survey (de Menezes et al., 2010).

The implications for research on high-involvement or, more generally, HRM systems are that we need to assess the relationship between practices as a first step, be mindful of the potentially discrete dimensions of HRM systems and expect the antecedents of these to vary. Indexes may be appropriate if there is little correlation between practices, but the practice of bundling them together without much consideration of the pattern of associations should be challenged. The differences in the results for customized production and the market variables are especially important in the light of the blanket expectation, induced by contingency theory, that one would expect the type of operation and market context of the organization to be the most important factor predicting both the use and success of high-involvement management. Moreover, the research reinforces Purcell's (1999) stress of the importance of business strategy and operations strategy, whilst 
industry, size and regional effects suggest that institutional factors may play a role. What lies behind these associations, and particularly those involving customization, needs investigating further, ideally with mixed methods. Longitudinal studies may add to this through understanding changes in the use of practices, as well as facilitating the monitoring of this over time.

Though the dataset does not include economic performance data, an analysis of a few human resource measures confirmed that their relationship to the dimensions of high-involvement management also varied across them (results available from the first author). For example, two training measures were only related (positively) to the skills-acquisition dimension, and skills deficiencies were negatively related to role involvement but positively related to skill acquisition (suggesting there is a reciprocal relationship between the two variables).

The first main limitation of the research is that the data is based on a single managerial respondent. The workplace venue for the research mitigates this problem to some extent, as we can expect the respondent to have a good idea of the practices in the workplace in the broad terms in which they are asked.

This high level of abstraction may be considered the second main limitation of the study. Practices such as team work and performance-related pay can take a variety of forms (Purcell, 1999) and be more or less well implemented. However, in this study, the practices are taken as indicative of an underlying orientation towards involvement or skill development. Studies of their nature would have to assess the various dimensions of particular practices - for example, is appraisal linked to pay and used to define training needs? It is likely that the predictors of the nature of particular practices would differ across the practices and not mirror directly the results of this study. 
A third more specific limitation is that there are only two role-involvement practices in the dataset. Measures that allow for different dimensions of discretion are available, which differentiate the extent to which individuals have control over what work they do, how much work they do, when they work on tasks, and how they work (Jackson, Wall, Martin, and Davids, 1993). Other measures of organizational involvement, such as team work and quality circles, have also been included in other studies of high-involvement management. Similarly, measures of motivational supports that are perhaps more specific to supporting involvement or skills acquisition have been used - for example job security guarantees, which have the potential to support idea-capturing schemes, and group pay systems, which may support team work.

The implications of the research for policy are twofold. First, that programmes to stimulate high-involvement management should highlight its various dimensions, role involvement, organizational involvement and skill acquisition. In contrast, the recent focus in UK public policy, for example, on engagement, may be too nebulous and illdefined. Second, the analysis of predictors may imply on the one hand that workplaces that most need this approach are adopting them and thus there is little need for policy intervention. On the other hand, it suggests that policies directed at stimulating production and quality methods such as TQM or lean production could increase the use of high-involvement practices, though this does not rule out policies directly aimed at high-involvement management. Perhaps targeting small workplaces may be timely, though their relative underuse of practices may reflect a reluctance that will make it more difficult to achieve big increases in use. Appeals to extend enriched jobs are perhaps best directed at manufacturing and these might highlight their benefits for well-being, performance and idea-generation. Although in our study 
role involvement is unrelated to TQM or lean production, there is sufficient evidence to suggest that giving workers more discretion enhances proactivity, idea-generation and the efficacy of the lean practices, so incorporating role involvement into the promotion of lean methods may not be misplaced.

\section{ACKNOWLEDGEMENTS}

UK Commission for Employment and Skills funded this research and the study is based on data from UK Commission's Employer Skills Survey of 2011, the main report of which is available on: https://www.gov.uk/government/publications/ukcesemployer-skills-survey-2011. The UK Commission for Employment and Skills do not have any responsibility for the analysis or interpretation of the material contained in this paper. We would like to thank Aoife Ni Luanaigh for her input to the design of the study and comments on earlier drafts of the paper. 


\section{REFERENCES}

Appelbaum, E., Bailey, T., Berg, P., and Kalleberg, A.L. (2000). Manufacturing Advantage: Why High Performance Work Systems Pay Off, Ithaca, NY, Cornell University Press.

Arthur, J.B. (1994). 'Effects of Human Resource Systems on Manufacturing Performance and Turnover' Academy of Management Journal, 7: 670-687.

Batt, R. (2000). 'Strategic segmentation in front-line services: matching customers, employees and human resource systems' International Journal of Human Resource Management, 11: 540-561.

Becker, B.E. and Huselid, M.A. (1998). 'High Performance Work Systems and Firm Performance: A Synthesis of Research and Managerial Implications', in GR Ferris (ed), Research in Personnel and Human Resource Management, Volume 16, Stamford, Connecticut: JAI Press.

Belt, V. and Giles, L. (2009). High Performance Working: A Synthesis of Key Literature, Evidence Report 4, London: UK Commission for Employment and Skills.

Benson, G.S. and Lawler, E.E. (2003). ‘Employee involvement: utilization, impacts and future prospect', in D Holman, T Wall, C Clegg, P Sparrow and A Howard (eds), The Essentials of the New Workplace, London: Wiley.

Bou, J.C. and Beltran, I. (2005). 'Total Quality Management, High-commitment Human Resource Strategy and Firm Performance: An Empirical Study' Total Quality Management, 16: 71-78.

Boxall, P. (2012). 'High-performance work systems: what, who and for whom?' Asia 
Pacific Journal of Human Resources, 50: 169-186.

Boxall, P. and Macky, K. (2009). 'Research and theory on high-performance work systems: Progressing the high-involvement stream' Human Resource Management Journal, 19: 3-23.

Boxall, P. and Purcell, J. (2003). Strategy and Human Resource Management, Basingstoke: Palgrave.

Cameron, A.C. and Trivedi, P.K. (2005). Microeconometrics: Methods and Applications, Cambridge: Cambridge University Press.

Datta, D.K., Guthrie, J.P. and Wright, P.M. (2005). 'Human Resource Management and Labor Productivity; Does Industry Matter?' Academy of Management Journal, 48: 135-145.

De Menezes, L. and Wood, S.J. (2006). 'The reality of flexible work systems in Britain' International Journal of Human Resource Management, 17: 106-138.

De Menezes, L., Wood, S. and Gelade, G. (2010). 'A longitudinal study of the latent class clusters of modern management practices and their association with organizational performance in British manufacturing' Operations Management, 28: $455-71$.

Deming, W. E. (1986). Out of the Crisis: Quality, Productivity and Competitive Position, Cambridge: Cambridge University Press.

DiMaggio, P.J. and Powell, W.W. (1991) 'Introduction', in PJ DiMaggio and WW Powell (eds) The New Institutionalism and Organizational Analysis, Chicago: University of Chicago Press. 
Dyer, L. and Holder, G. W. (1988). 'A strategic perspective on human resource management', in L Dyer and GW Holder (eds), Human resource management: Evolving roles and responsibilities, Washington DE: The Bureau of National Affairs, Inc.

Gerhart, B. (2007). 'Horizontal and vertical fit in Human Resource Systems', in C Ostroff and TA Judge (eds), Perspectives on Organizational Fit, New York and London: Lawrence Erlbaum.

Guest, D. (2011). 'Human resource management and performance: still searching for some answers' Human Resource Management Journal, 21: 3-13.

Guest, D. and Hoque, K. (1994). 'The Good, the Bad and the Ugly: Employee Relations in New Non-union Workplaces' Human Resource Management Journal, 5: 1-14.

Gwinner, K. P., Bitner, M. J., Brown, S. W. and Kumar, A. (2005). 'Service Customization through Employee Adaptiveness' Journal of Service Research, 8: $131-148$.

Hong, Y., Liao, H., Sturman, M. C. and Zhou, Y. (2013). 'Competing through customization: Using human resource management to create strategic capabilities' Organizational Psychology Review, 4: 1-24.

Hoque, K. (1999). 'Human resource management and performance in the UK hotel industry' British Journal of Industrial Relations, 37: 419-443.

Huselid, M. A. (1995). 'The impact of human resource management practices on turnover, productivity, and corporate financial performance' Academy of Management Journal, 38: 635-672. 
Jackson, P. R., Wall, T. D., Martin, R. and Davids, K. (1993). 'New measures of job control, cognitive demand, and production responsibility' Journal of Applied Psychology, 78: 753-762.

Kalleberg, A. L., Marsden, P. V., Reynolds, J. and Knoke, D. (2006). 'Beyond profit? Sectoral differences in high-performance work practices' Work and Occupations, 33: 271-302.

Kufidu, S. and Vouzas, F. (1998). 'Human Resource Aspects of Quality Management: Evidence From MNEs Operating in Greece' International Journal of Human Resource Management, 9: 818-30.

Lawler, E.E. (1986). High-involvement Management, San Francisco: Jossey-Bass.

MacDuffie, J.P. (1995). 'Human resource bundles and manufacturing performance: Organizational logic and flexible production systems in the world auto industry' Industrial and Labor Relations Review, 48: 197-221.

Porter, M.E. (1980). Competitive Strategy: techniques for analyzing industries and competitors, New York: Free Press.

Purcell, J. (1999). 'Best practice and best fit: chimera or cul-de-sac'. Human Resource Management Journal, 9: 26-41.

Scherkenbach, W. W. (1991). The Deming Route to Quality and Productiuity. London: Mercury Books.

Scholtes, P. R. (1987). An Elaboration on Deming's Teachings on Performance Appraisal. Madison: Joiner Associates. 
Schuler, R. and Jackson, S. (1987). 'Linking competitive strategies and human resource management practices' Academy of Management Executive, 1: 207219.

Subramony, M. (2009). 'A meta-analytic investigation of the relationship between HRM bundles and firm performance' Human Resource Management, 48: 745768.

Wall, T.D., Wood, S., and Leach, D. (2004). 'Empowerment and performance', in I Robertson and C Cooper (eds), International Review of Industrial and Organizational Psychology 19, London: Wiley.

Wall, T. and Wood, S. (2005). 'The romance of human resource management and business performance, and the case for big science', Human Relations, 58, 429_ 462 (Reprinted in N Anderson (ed) (2007), Fundamentals of HRM: Sages Major Works 4, London: Sage,).

Walton, R. (1985). 'From "control" to "commitment" in the workplace' Harvard Business Review, 63: 77-84.

Way, S.A. (2002). 'High Performance Work Systems and Intermediate Indicators of Firm Performance within the US Small Business Sector' Journal of Management, 28: 765-785.

West, M.A., Guthrie, J.P., Dawson, J.F., Borrill, C.S. and Carter, M. (2006). 'Reducing patient mortality in hospitals: The role of human resource management' Journal of Organizational Behaviour, 27, 983-1002.

Wood, S. (1991). 'Japanization and/or Toyotaism?' Work, Employment and Society, 5: $567-600$ 
Wood, S. (1999). 'Human resource management and performance' International Journal of Management Reviews, 1: 367-413.

Wood, S. (2009). 'High involvement management and performance', in A Wilkinson, P Gollan, M Marchington and D Lewin (eds), The Oxford Handbook of Participation in Organizations, Oxford and New York: Oxford University Press.

Wood, S. and Bryson, A. (2009). 'High involvement management', in W Brown, A Bryson, J Forth and K Whitfield (eds), The Evolution of the Modern Workplace, Cambridge: Cambridge University Press.

Wood, S. and de Menezes, L. (2008). 'Comparing perspectives on high involvement management and organizational performance across the British economy' International Journal of Human Resource Management, 19: 639-683.

Wood, S. and Wall, T. (2007). 'Work enrichment and employee voice in human resource management-performance studies' International Journal of Human Resource Management, 18: 1335-1372.

Wood, S., van Veldhoven, M., Croon M. and de Menezes, L. M. (2012). 'Enriched job design, high involvement management and organizational performance: The mediating roles of job satisfaction and well-being' Human Relations, 65: 419446. 
Table 1: Predictors of High-Involvement Management Dimensions (whole economy)

\begin{tabular}{|c|c|c|c|c|c|c|}
\hline Dependent Variable & Role & Ivement & & $\begin{array}{l}\text { zational } \\
\text { ement }\end{array}$ & Skills & quisition \\
\hline Independent Variable & $\begin{array}{l}\text { Beta } \\
\text { Coeff }\end{array}$ & t-value & $\begin{array}{l}\text { Beta } \\
\text { Coeff }\end{array}$ & t-value & $\begin{array}{l}\text { Beta } \\
\text { Coeff }\end{array}$ & t-value \\
\hline Size 1-4 & .732 & $11.41 * *$ & -1.192 & $-43.85 * *$ & -.773 & $-40.14 * *$ \\
\hline Size 5-9 & .496 & $7.80^{* *}$ & -.856 & $-41.45^{* *}$ & -.337 & $-23.50 * *$ \\
\hline Size $10-24$ & .321 & $5.06 * *$ & -.098 & $-5.00 * *$ & -.160 & $-12.42 * *$ \\
\hline Size $25-49$ & .237 & $3.70^{* *}$ & -.060 & $-3.01 * *$ & -.050 & $-4.00 * *$ \\
\hline Size 50-99 & .140 & $2.13^{*}$ & -.050 & $-2.40 *$ & -.022 & -1.75 \\
\hline Size 100-249 & .011 & 0.16 & .006 & 0.27 & -.0001 & -0.01 \\
\hline Size $>=250$ & & & & & & \\
\hline Primary & .098 & $2.62 * *$ & -.380 & $-6.66 * *$ & -.054 & -1.23 \\
\hline Manufacturing & -.068 & $-2.59 *$ & -.174 & $-8.34 * *$ & -.230 & $-11.36 * *$ \\
\hline Construction & -.011 & -0.51 & -.305 & $-10.62 * *$ & -.115 & $-4.69 * *$ \\
\hline Public Services & .190 & $7.58^{* *}$ & .240 & $17.00 * *$ & .176 & $11.95 * *$ \\
\hline Private Services & & & & & & \\
\hline Standardized production & -.195 & $-10.67 * *$ & -.023 & -1.50 & -.092 & $-5.76 * *$ \\
\hline Partial customization & -.233 & $-12.00 * *$ & .008 & 0.54 & -.008 & -0.51 \\
\hline Customization & & & & & & \\
\hline Total quality management & .018 & 0.82 & .225 & $15.72 * *$ & .169 & $11.94 * *$ \\
\hline
\end{tabular}




\begin{tabular}{|l|c|c|c|c|c|c|}
\hline Northern Ireland & -.096 & $-2.10^{*}$ & -.037 & -1.30 & .083 & $2.26^{*}$ \\
\hline Scotland & -.015 & -.043 & .004 & 0.17 & .068 & $2.47^{*}$ \\
\hline Wales & -.065 & $-2.26^{*}$ & -.063 & $-2.63^{* *}$ & -.019 & -0.84 \\
\hline England & & & & & & \\
\hline Part of a larger organization & -.086 & $-4.97^{* *}$ & .996 & $65.26^{* *}$ & .305 & $21.95^{* *}$ \\
\hline Constant & & & & & & \\
& -.411 & $-6.32^{* *}$ & .630 & $24.31^{* *}$ & 1.501 & $76.79^{* *}$ \\
\hline F-Stat & & & & & & \\
\hline
\end{tabular}

* $=p<.05,{ }^{* *}=p<.01$ 
Table 2: Predictors of High-Involvement Management Dimensions with inclusion of strategy variables (Private Sector)

\begin{tabular}{|c|c|c|c|c|c|c|}
\hline \multirow{2}{*}{ Dependent Variable } & \multicolumn{2}{|c|}{ Role involvement } & \multicolumn{2}{|c|}{ Organizational Involvement } & \multicolumn{2}{|c|}{ Skills Acquisition } \\
\hline & $\begin{array}{l}\text { Beta } \\
\text { Coeff. }\end{array}$ & t-value & $\begin{array}{l}\text { Beta } \\
\text { Coeff. }\end{array}$ & t-value & $\begin{array}{l}\text { Beta } \\
\text { Coeff. }\end{array}$ & t-value \\
\hline Size 1-4 & .740 & $8.20 * *$ & -1.275 & $-35.48 * *$ & -.819 & $-33.96 * *$ \\
\hline Size 5-9 & .487 & $5.44^{* *}$ & -.818 & $-30.86 * *$ & -.362 & $-19.58 * *$ \\
\hline Size $10-24$ & .304 & $3.40 * *$ & -.053 & $-2.11^{*}$ & -.175 & $-10.37 * *$ \\
\hline Size 25-49 & .186 & $2.06^{*}$ & -.036 & -1.40 & -.059 & $-3.56 * *$ \\
\hline Size 50-99 & .082 & 0.89 & -.043 & -1.62 & -.033 & $-1.99 *$ \\
\hline Size $100-249$ & -.051 & -0.52 & -.031 & -1.10 & -.027 & -1.57 \\
\hline \multicolumn{7}{|l|}{ Size $>=250$} \\
\hline Primary & .120 & $3.21 * *$ & -.299 & $-4.97 * *$ & -.022 & -0.49 \\
\hline Manufacturing & -.050 & -1.84 & -.114 & $-5.33 * *$ & -.199 & $-9.67 * *$ \\
\hline Construction & .015 & 0.65 & -.183 & $-6.21 * *$ & -.059 & $-2.33^{*}$ \\
\hline \multicolumn{7}{|l|}{ Public Services } \\
\hline \multicolumn{7}{|l|}{ Private Services } \\
\hline Standardized production & -.170 & $-8.12 * *$ & -.003 & -0.15 & -.067 & $-3.54 * *$ \\
\hline Partial customization & -.209 & $-9.56 * *$ & .045 & $2.50 *$ & .025 & 1.37 \\
\hline Customization & & & & & & \\
\hline
\end{tabular}




\begin{tabular}{|c|c|c|c|c|c|c|}
\hline Total quality management & .015 & 0.61 & .254 & $15.53^{* *}$ & .189 & $12.02 * *$ \\
\hline Non-price competition & .006 & 0.82 & -.007 & -1.36 & -.003 & -0.56 \\
\hline Product leadership & .018 & $2.88 * *$ & .058 & $9.83 * *$ & .025 & $4.05 * *$ \\
\hline Competing on Quality & .049 & $5.83 * *$ & .035 & $5.24 * *$ & .029 & $4.14^{* *}$ \\
\hline Northern Ireland & -.101 & -1.86 & -.009 & -0.23 & .108 & $2.24^{*}$ \\
\hline Scotland & -.007 & -0.19 & .055 & 1.62 & .089 & $2.67 * *$ \\
\hline Wales & -.074 & $-2.26^{*}$ & -.085 & $-2.90 * *$ & -.033 & -1.22 \\
\hline \multicolumn{7}{|l|}{ England } \\
\hline Part of a larger organization & -.135 & $-6.58 * *$ & .981 & $52.21 * *$ & .279 & $17.37^{* *}$ \\
\hline Constant & -.700 & $-7.06 * *$ & .224 & $5.03 * *$ & 1.290 & $31.42 * *$ \\
\hline F-stat & \multicolumn{2}{|c|}{$112.28^{* *}$} & \multicolumn{2}{|c|}{$1595.84 * *$} & \multicolumn{2}{|c|}{$421.39 * *$} \\
\hline
\end{tabular}

* $=p<.05,{ }^{* *}=p<.01$ 